\title{
DESENHAR UMA ACADEMIA: MODERNISMO E AUTONOMIA FORMAL NOS BASTIDORES DA ESCOLA NACIONAL DE BELAS ARTES DURANTE A 1a REPÚBLICA
}

\author{
Arthur Valle \\ Doutor em História e Crítica da Arte - Programa de Pós-Graduação em \\ Artes Visuais - EBA/UFRJ \\ Vínculo institucional: Instituto Superior de Educação / Fundação de Apoio \\ à Escola Técnica (ISE/Faetec)
}

Partindo da descrição de como se dava o processo de desenho de uma academia na Escola Nacional de Belas Artes (ENBA) do Rio de Janeiro durante a 1a República (1889-1930), a presente comunicação procura discutir algumas convergências formais verificáveis entre obras produzidas no contexto das instituições oficias de ensino artístico a partir do século XIX e aquelas normalmente identificadas com os correntes artísticas chamadas modernistas.

A noção de Modernismo a qual faremos referência aqui é bastante específica, apenas uma entre outras possíveis - mas, não obstante, ainda hoje talvez a mais difundida e influente ${ }^{1}$. Segundo essa noção, as artes modernistas se caracterizam pelo seu caráter auto-crítico, bem como pela sua autonomia, seja com relação à natureza, seja no âmbito das suas diversas modalidades - pintura, escultura, literatura, música, etc. Tal noção encontrou a sua mais conhecida formulação nos anos 1940, em textos célebres do crítico norte-americano Clement Greenberg, que postulava como a conseqüência extrema do movimento modernista justamente a eliminação, em cada arte, de "todo e qualquer efeito que se pudesse imaginar ter sido tomado dos meios de qualquer outra arte ou obtido por meio deles. Assim cada arte se tornaria 'pura' e nessa 'pureza' iria encontrar a garantia de seus padrões de qualidade bem como de sua independência"n.

Hoje em dia, parte dos historiadores e críticos de arte brasileiros reconhecem que uma consciência da autonomia da pintura, nos termos acima definidos, se encontrava madura, no primeiro período republicano,

\footnotetext{
Cf., por exemplo, o sentido "habitual e um tanto confuso" de Modernismo resumido por Timothy J. Clark em A Pintura da vida moderna: Paris na arte de Manet e seus seguidores. São Paulo: Companhia das Letras, 2004, pp.44.sg

2 GREENBERG, C. Pintura Modernista. In: FERREIRA, G; MELLO, C. Clement Greenbery e o Debate Crítico. Rio de Janeiro: Jorge Zahar, 1997, p.102.
} 
entre os artistas ligados à ENBA. Paulo Herkenhoff é um dos que defende a idéia de que, na obra destes últimos, é possível encontrar "uma consciência moderna da superficie mais radical do que tudo que se exporia na Semana [de Arte Moderna de 1922]"3. Essa opinião encontra eco em textos de outros estudiosos, nos quais uma "consciência moderna da superfície" é percebida especialmente nas pinturas de paisagem feitas pelos artistas acadêmicos do período. É nesse sentido que Tadeu Chiarelli se refere em alguns de seus textos às paisagens de pintores relacionados de maneira mais ou menos estreita com a ENBA como portadoras de uma fatura mais "moderna" do que aquela encontrada na obra de boa parte dos próprios modernistas brasileiros. Segundo Chiarelli, as marinhas de um artista como G. B. Castagneto, por exemplo, "possuem muitas das características indicadoras da pintura moderna: cada um dos elementos formais que as compõem obedece à urgências intrinsecas da própria pintura"4.

Aqui, procuraremos ampliar tais considerações, demonstrando como algumas dessas "características indicadoras da pintura moderna" podem também - e talvez com mais propriedade -, ser percebidas em obras produzidas no próprio seio do ensino acadêmico fluminense. É o caso de nosso objeto de considerações no presente artigo, os desenhos feitos a partir do modelo vivo, mais conhecidos como academias. Uma análise do processo de execução de uma academia desenhada, como era conduzido pelos freqüentadores da ENBA durante a $1^{\text {a }}$ República, permite revelar que na realização desse exercício pedagógico aparentemente prosaico os artistas acadêmicos se encontravam imbuídos de uma consciência operativa da autonomia dos meios formais em diversos aspectos análoga àquela postulada pela teoria modernista a qual acima fizemos referência.

Considerações iniciais - Logo de início, é importante destacar que duas orientações fundamentais se encontravam na base da realização dos desenhos de academia na ENBA: a primeira dizia respeito à realização do desenho no seu sentido mais amplo, determinando que esta deveria seguir uma lógica que ia do geral para o particular; a segunda se referia à divisão da

3 HERKENHOFF, P. Arte Brasileira na Coleção Fadel: da Inquietação do Moderno à Autonomia da Linguagem. Rio de Janeiro: Andrea Jakobsson Estúdio, 2002 (Catálogo de exposição), p.25.

${ }^{4}$ CHIARELLI, T. Entre Almeida Jr e Picasso. In: FABRIS, A. (org.). Modernidade e Modernismo no Brasil. São Paulo: Editora Mercado das Letras, 1994, p.57. 
realização do desenho em duas fases, uma destinada à configuração do contorno linear e a outra à do modelado (claro-escuro).

A primeira dessas orientações respondia àquelas exigências de organicidade da obra de arte, expressas já pelos primeiros românticos, como A. J. Carstens e P. O. Runge, e que, durante o século XIX, se fariam ouvir dentro dos próprios meios acadêmicos, se expressando de forma evidente no desenho de modelo vivo. Um apelo em prol da organicidade pode ser verificado, por exemplo, em uma passagem do tratado The painter in oil (Boston, 1898), do pintor norte-americano Daniel Burleigh Parkhurst, que fora um aluno de W. A. Bouguereau, na Paris de finais do Oitocentos: "Todo bom trabalho vai do geral para o particular, das massas para os detalhes. Guarde isso em mente como um principio fundamental no bom trabalbo, seja de que espécie for. $V$ ocê nunca deveria colocar um detalhe antes de ter colocado as suas grandes massas. $A$ importância relativa das coisas depende primeiro do que é mais importante. Faça com que essa seja a sua primeira regra ao desenhar"'.5.

No Brasil, é possível observar uma preocupação similar. Juntamente com a extinção da cópia de gravuras verificada no início da $1^{\mathrm{a}}$ República, o ensino do desenho deixara de principiar com o aprendizado de detalhes anatômicos isolados. Passava-se então diretamente aos desenhos de moldes de gesso e estes, mesmo que representassem fragmentos da figura, valiam essencialmente como uma iniciação às questões do claroescuro. Algumas décadas mais tarde, a pintora Georgina de Albuquerque defenderia como uma das "regras que auxiliam a pratica" de todo tipo de desenho, "proceder sempre do conjunto ao detalhe, de maneira a poder parar em qualquer momento, dando o desenho a justa impressão de estar sendo feito com inteligência e entendimento"'.

Quanto a segunda orientação acima referida, relativa à divisão da realização do desenho em duas fase distintas - uma destinada ao traçado do contorno linear da figura, outra ao seu modelado -, a orientação pedagógica vigente na ENBA durante 1a República seguia uma tradição cujas origens remontam ao século XVI, promovendo o "pacto" entre o conceito romano-florentino de desenho com a ênfase posta sobre o contorno e a concepção veneziana na qual prevalecia o diálogo construtivo entre luz e

\footnotetext{
5 Chapter XVI: Proportion. In: PARKHURST, D. B. The Painter in Oil. Texto disponível no site: http://www.artrenewal.org/articles/2002/Parkhurst/parkhurst1.asp

6 ALBUQUerque, Georgina de. O Desenho Como Base no Ensino das Artes Plásticas. Rio de Janeiro: ENBA, 1942, p.17.

Disponível no site: http://www.dezenovevinte.net/txt_artistas/ga_desenho.pdf
} 
sombra ${ }^{7}$. Por vezes, essa concepção da execução do desenho cindida em duas fases se encontrava explicitada nos próprios planos de ensino vigentes na 1a República: é o caso de um programa para a aula de modelo vivo datado de 1900, no qual João Zeferino da Costa propôs uma separação dos seus alunos em duas turmas distintas, com base na idéia de divisão graduada entre desenho linear e desenho sombreado ${ }^{8}$.

“Movimento" - Entre as orientações acima resumidas, a primeira - a aplicação de uma lógica que ia do geral para o particular -, era prioritária, sendo verificável nos estágios mais elementares de execução de uma academia, bem antes das questões relativas ao modelado entrarem em jogo. Uma boa descrição, apesar de um tanto tardia, de como os artistas da $1^{\text {a }}$ República procediam na representação do modelo vivo pode ser encontrada em uma tese de Henrique Cavalleiro, nas qual o pintor aconselhava, como uma das primeiras normas a seguir no desenho de uma academia, "Determinar e bem caracterisar o movimento geral da figura, o qual se fórma pelas linhas principais de direção, linhas essas correspondentes aos eixos do tronco, dos ombros, da bacia, das pernas e dos bracos, o que constitue o mecanismo do corpo bumano"'.

Exemplos do que os artistas então entendiam pelo termo "movimento" podem ser encontrados em desenhos de Zeferino da Costa que ilustram seu tratado sobre os mecanismos da figura humana e que mostam as "linhas de direção" de figuras em deslocamento ${ }^{10}$, bem como em desenhos de Cavalleiro reproduzidos na sua citada tese que "demonstram, por seu traçado, como se deve construir o arcabonço inicial de uma 'academia' on

\footnotetext{
${ }^{7}$ Como observou Juan Bordes, essa divisão é muito usual nos manuais e cartilhas de ensino artístico surgidas a partir do século XV: "Sin embargo, muchos métodos separan ambas concepciones como dos etapas de un mismo dibujo, y hacen convivir en la misma lámina dos estados de un modelo, uno a contorno y otro modelado" (BORDES, J. Historia de las teorias de la figura humana: El dibujo/ la anatomía/ la proporcíon/ la fisiognomía. Madrid: Cátedra, 2003, p.70).

8 Acervo arquivístico do Museu Dom João VI. Notação 5341: Proposta de Programma para a aula de Modelo vivo da mesma Escola apresentada pelo professor interino da referida aula - João Zeferino da Costa, 14 de março de 1900, folha 1 verso.

9 CAVAlleiro, H. Da Didática e da Técnica da Pintura - Considerações sôbre alguns problemas. Rio de Janeiro: ENBA, 1952, pp.37-38 (Tese de concurso); texto disponível no site: http://www.dezenovevinte.net/txt_artistas/txt_cavalleiro_1952.htm

${ }^{10}$ COSTA, João Zeferino da. Mecanismo e proporções da figura humana. In: Arquivos da Escola Nacional de Belas Artes. Rio de Janeiro: Universidade do Brasil, 1956, pp.40 e 42. Disponível no site: http://www.dezenovevinte.net/txt_artistas/jzc_proporcoes.pdf
} 
figura"11. Nos dois casos, o "movimento" é indicado por linhas auxiliares que correspondem grosso modo a eixos anatômicos fundamentais da figura. Essa linhas tinham a função de guiar o contorno linear propriamente dito e de tal modo se integravam ao resto do desenho, no processo de sua realização, que, de maneira geral, são imperceptíveis no seu estágio final. Provas adicionais de que a boa caracterização do "movimento" era um fator considerado crucial na avaliação de uma academia podem ser encontradas em alguns pareceres da ENBA, especialmente naqueles referentes aos Prêmios de Viagem ao Estrangeiro datados das décadas inicais da $1^{a}$ República - o que indica que, desde então, o conceito se encontrava firmemente estabelecido na Academia fluminense ${ }^{12}$.

Os artistas tradicionalmente atribuíram grande importância à qualidade que nossos acadêmicos designavam como "movimento", porém, na pedagogia da École des Beaux Arts de Paris, essa preocupação se tornou ainda mais proeminente e sistematizada com os programas posteriores a Reforma de 1863, quando se desenvolveu um esforço no sentido de racionalizar o ensino que estimulou uma abordagem "científica" na representação de formas, atitudes e movimentos. Um estudioso como Albert Boime defende que a relação entre a instrução artística e as inovações das chamadas correntes independentes na segunda metade do século XIX foram em boa parte mediadas por essa reforma pedagógica que visava promover a indústria artística francesa, bem como a planejada remodelação de Paris ${ }^{13}$. Nesse sentido, a concepção de "movimento" professada nos meios oficiais pode ser considerada um exemplo típico das vias pelas quais se estabeleceram relações entre a didática da academia parisiense e a estética de alguns artistas independentes.

${ }^{11}$ CAVAlleiro, H. Op. cit., n/p.

${ }^{12}$ Dois exemplos: no julgamentos das provas ao Premio de Viagem de 1893, as academias pintadas dos candidatos classificados em segundo e terceiro lugar são elogiadas justamente no que concerne à compreensão do "movimento" (Acervo arquivístico do Museu Dom João VI. Notação 6154: Acta da secção do Conselho Escolar em 2 de dezembro de 1893, p.23 verso). Já no concurso de 1906, os membros da comissão julgadora elogiaram o trabalho de Lucílio de Albuquerque por apresentar a "indispensável lógica entre o movimento do protagonista e os acessórios que completam a scena" (Acervo arquivístico do Museu Dom João VI EBA/UFRJ. Notação 6155: Acta da sessão do Conselho Escolar realizada no dia 8 de fevereiro de 1906, p.25 verso). Transcrições disponíveis no site http://www.dezenovevinte.net/documentos/pareceres.htm

${ }^{13}$ Cf. BOIME, A. The teaching of fine arts and the avant-garde in France during the second half of the nineteenth century. In: Las academias de arte (VII Coloquio Interncional de Gaunajuato). D.F.: Univesidad Autónoma do Mexico, 1985. 
No sentido que estamos aqui discutindo, isso se manisfestva, por exemplo, no esforço, comum a acadêmicos e independentes, de caracterizar um gesto ou uma atitude através da chamada "linha de ação", "o ritmo vital do corpo reduzido a uma linha abstrata central em torno da qual a ação é organizada"14. J. L. Gerôme era um dos mestres da École que professava essa orientação. Um de seus mais destacados discípulos, o pintor americano Thomas Eakins, assimilou tal método e fez fotorafias de modelos, que posteriormente eram reduzidos a desenhos lineares, afim de evidenciar a suas "linhas de ação". A identificação desse ritmo visava, como Eakins declarava, garantir a harmonia da obra: desde que o "movimento" da figura tivesse sido corretamente captado, cada detalhe da ação seria uma parte orgânica e integrada na ação principal ${ }^{15}$.

Os primeiros trabalhos de Georges Seurat, realizados na Ecole Lequien, indicam uma preocupação análoga com o "movimento" da figura, bem como com o papel das sombras em acentuá-lo. Nesse sentido específico, é importante lembrar ainda da influência de um autor muito prezado por Seurat, o matemático, paisagista e filósofo da arte David Sutter, que em sua Esthétique Generale et appliquée (Paris, 1865) - obra altamente recomendada por figuras de relevo nos círculos oficiais como Charles Blanc -, frisava noções como as de "unidade óptica" e "dominantes direcionais". Tais preocupações seriam constantes na carreira de Seurat, em especial em sua fase madura ${ }^{16}$, e se encontram na base de suas por vezes caricaturais configurações da figura humana.

Já em pleno século XX, os desenhos do natural feitos por Henri Matisse na Académie Julian, sob a orientação de Bouguerau e outros acadêmicos, revelam um conhecimento da "linha de ação". A preocupação com o "movimento" e com seu papel na caracterização expressiva dos motivos foi também central para o pintor de origem russo Wassily Kandinsky, frequentador da Academia de Munique e um dos primeiros abstracionistas. Alguns desenhos realizados quando Kandinsky lecionava na Bauhaus de Weimar tem uma intenção claramente didática e são representativos do processo de redução de determinados motivos ao seu "movimento" geral.

${ }^{14}$ Idem, p.185.

${ }_{15}$ Citado em BOIME, A. Idem, p.192.

${ }^{16}$ As soluções diagramáticas proposta por Sutter para composições com uma dominante horizontal parecem ter contribuído na elaboração de obras célebres de Seurat, com Banbistas em Asnières ou Domingo á tarde na ilha da Grande Jatte . 
São evidentes as analogias entre esses desenhos de Kandinsky e aqueles de Zeferino da Costa acima referidos. Certamente, Kandinsky encarava o "movimento" em termos um tanto diversos, como uma realidade plástica autônoma, e inclusive propunha a substituição do termo, insatisfeito com a sua natureza metafórica ${ }^{17}$. Em virtude disso, seus desenhos são um fim em si mesmos e não esquemas para posteriores desdobramenos, como no caso dos do mestre brasileiro; além disso, Kandinsky não os pensava como uma simples decorrência dos "mecanismos" da figura, como faziam Zeferino ou mesmo Henrique Cavalleiro. Não obstante, fica patente uma afinidade de abordagem que, em última análise, parece decorrer de um traço de longa duração da pedagogia acadêmica - basta lembrar dos esquemas de "movimento" propostos por tratadistas como Lairesse e Preissler, feitos séculos antes, para comprovar tal fato ${ }^{18}$.

A marcação linear - Os "arcabouço iniciais" de Cavalleiro indicam que, depois de verificar o "movimento" geral da figura, o artista devia se voltar para o traçado do seu contorno linear propriamente dito. Esse deveria seguir aquela lógica do todo para a parte, já bastante referida: em um primeiro momento, o contorno era realizado com linhas simplificadas, de caráter francamente geométrico, que davam conta apenas das suas direções principais. Em seu livro sobre os manuais de desenho da figura, Juan Bordes designou com a expresão traz̧o recto essa marcação esquemática, como a que aparece nas figuras de Cavalleiro. Nos ateliês franceses oitocentistas ela era mais conhecida, todavia pela expressão mise en trait. como observa Boime, o mise en trait era uma forma tosca de esboço, cuja função essencial era prover uma base para um traçado mais refinado ${ }^{19}$. De acordo com essa noção, Parkhurst aconselhava: "Veja os contornos primeiramente em termos de linhas retas e ângulos. [...] Não que as linhas retas devam ser buscadas como um fim em si mesmas, mas apenas como um meio de simplificar uma primeira divisão do todo em partes, e assim fazendo tornar mais fácil o estudo da proporção"20

\footnotetext{
${ }^{17}$ Cf. KANDINSKY, W. Punto y linea sobre el plano. Barcelona: Barral Editores, 1974,p.58.

${ }^{18}$ Cf. BORDES, J. Op. cit., pp.76-77, figuras 4-6 e 8.

${ }^{19}$ A passagem original de Boime é a seguinte: "It is essential to emphasize that the mise en trait was a form of rough sketch aimed at providing a base for a careful finishing" (BOIME, A. Op.cit., p.26).

20 “Chapter XVI: Drawing”. In: PARKHUSRT, D. B. Op.cit.
} 
Entre inúmeros outros, um exemplo didático do processo de execução do contorno linear de uma figura pode ser observado no mise em trait e na versão mais acabada de uma cabeça do "antigo", extraídos do Méthode de dessin (1867) de autoria do pintor francês Adolphe Yvon. Nesses desenhos é ainda possível observar o uso de linhas auxiliares para indicar as divisões principais do perfil e como guia do "movimento" do seu contorno geral. O recurso ao mise en trait é certamente bem antigo: ao menos na França, ele parece remontar ao século XVII ${ }^{21}$, e, segundo Bordes, "é utilizado por Preisler [Die durch theorie enfurdene Practic..., Nürnberg, 1721-25] e se torna habitual no métodos do século XIX, como o de Esplugas y Gual [Preámbulo al nuevo método para la enseñanza del dibujo natural..., Barcelona, 1854] ou o de Ducollet [Les classiques du Louvre, Paris, 18-] que recolhe detalhes de pinturas do Louvre e se anuncia como modelos em grandes traços e com silhueta quadrada"22.

No final da década de 1860, respondendo aos desejos acima referidos de reforma do sistema de ensino artístico francês, um outro discípulo de Gérôme, Charles Bargue, elaborou uma série 300 desenhos litografados em grande folio, publicados em três volumes ${ }^{23}$. Tais desenhos eram graduados em complexidade e, apesar de seguir a tradicional ordem dos modelos do ensino acadêmico - primeiro desenhos a partir de moldagens de gesso; depois, segundo os mestres antigos; e, por fim, a partir do modelo vivo -, Bargue defendia uma abordagem mais livre, "recomendava o uso do esfuminho e do carvão, empregava geometria para construir a figura e projetar sombras, e enfatizava as linhas essenciais"24. J. L. Forain e V. Van Gogh foram apenas dois dos celebrados artistas independentes que estudaram a partir dos livros de Bargue. Em seu esforço de autoformação, Van Gogh copiava assiduamente os exercícios de Bargue, considerando o método especialmente valioso, pois "ele fornecia 'apenas linhas e massas gerais, e simples, delicados contornos' e o ensinou a procurar na natureza 'por linhas gerais'. Sob a influência de Bargue ele podia escrever que copiar uma imagem tinha uma vantagem sobre copiar do natural no sentido em que permitia que se captasse

\footnotetext{
${ }^{21}$ Boime cita a obra de Roger de Piles Les premiers élémens de la peinture pratique (Paris, 1684).

22 BORDES, J. Op. cit., p.71.

${ }^{23}$ BARGUE, C. Cours de dessin, executé avec le concours de Gérôme. I. Modèles d'après la bosse; II. Modèles d'après les maîtres de toutes les èpoques et toutes les écoles; III. Exercices au fusain pour préparer à l'étude de l'académie d'après nature. Paris: Goupil et Cie., 1868-1870, referido em BORDES, J. Op. cit., p.112); existe pelo menos uma segunda edição, de 1871.

${ }^{24}$ BOIME, A. Op. cit., p.190.
} 
imediatamente as 'linhas essenciais'. Isso ajudou inclusive seus deenhos de paisagem; como confessou: 'Aprendi a compreender a natureza através dos Bargues"'25.

No Brasil, o recurso ao mise em trait na execução do contorno linear pode ser observada em exemplos bem anteriores àqueles fornecidos por Cavalleiro. Provavelmente, ele remonta aos tempos imperiais e pode ser confirmado, já na primeira década da República, em uma série de trabalhos de diversos estudantes da ENBA. Normalmente, podemos encontrar essas marcações iniciais como pequenos esboços, nas margens de folhas com desenhos mais acabados, ou como a versão inicial de um desenho que, por algum eventual motivo, não foi levado a cabo.

Feita essa marcação primária, que davia dar conta da totalidade da figura, restava ao artista configurar as variações mais sutis de direção perceptíveis no contorno. Esse detalhamento podia anteceder ou mesmo ser feito em paralelo com a fase final da academia, a execução do modelado. A partir de finais do século XIX, porém, diversos artistas passaram a manter até a finalização de seus trabalhos um contorno sintético e geometrizado que remetia ao aspecto do mise en trait. Isso pode ser verificado em muitas figuras do citado Van Gogh e nas de pintores como Pablo Picasso, os alemães do grupo Die Brücke, Max Beckmann, entre outros. Em tais casos, a deliberada manutenção de um contorno estilizado foi interpretada como uma atitude eminentemente modernista, que ia na contra-mão das nocão de representação e verossimilhança. Porém, a própria formação desses artistas, com seus comprovados laços com as instituições acadêmicas das principais cidades européias (Dresden, Barcelona, etc) nos leva a supor que, na adoção desse partido, um não desprezível crédito deveria ser dado a pedagogia ministrada nas academias.

O modelado: Effet e Modernismo - O modelado da figura, ou seja, a configuração do jogo de luz e sombra, era o principal fator responsável pela sugestão de relevo e concretude nas academias. Já o treinamento a partir das moldagens de gesso tinha como um dos seus objetivos principais fazer com que o estudante incrementasse a sua percepção das variações de claroescuro, que eram também designadas pelos termos meias-tintas (demi-teintes) ou valores. Em outra passagem da sua tese, Henrique Cavalleiro procurava justamente especificar o significado desse último termo: "Em pintura, os valôres dependem da intensidade luminosa da côr dos objétos, em relação à escala que vai

${ }^{25}$ Idem, p.191. 
do branco ao preto e considerada como limites extremos da escala cromática. Em desenho, dependem exclusivamente daquela escald"26

Desde os tempos de J. L. David, a pedagogia acadêmica enfatizava, simultaneamente, a obtenção de um modelado graduado através da delicada sucessão de meias-tintas e de um contraste vigoroso entre os planos unificados de valores luminosos e escuros - contraste designado nos ateliês franceses pelo termo effet ${ }^{27}$. Assim como com relação à marcação linear, o trabalho com os valores deveria seguir a lógica do todo para a parte e a questão primordial era, portanto, determinar a organização geral da distribuição dos valores. Por isso, dava-se prioridade à configuração do effet : "Não se deve dar atenção às meio-tintas e aos detalhes até que você tenha tratado das grandes massas" 28 , já aconselhava o Manuel du dessinateur de A. M. Perrot (Paris, 1832). Uma preocupação antecipada com a definição dos detalhes invariavelmente levava o aprendiz a configurá-los fora da hierarquia de valores do conjunto. Dentro desse espírito, Georgina de Albuquerque exporia, na sua já citada tese, uma interpretação da orientação acadêmica a respeito da questão: "Para praticar em desenho o estudo dos valores, de inicio é preciso limital-o á apenas dois: a) - sombra b) - lu₹. Reservado para as partes em luzo branco do papel, desenha-se o contorno da sombra com o cuidado como se desenha o contorno do objétos enchendo-se em seguida o espaço em sombra com um valor igual' 29.

O processo mais eficaz para determinar as grandes massas de luz e sombra, ignorando em um primeiro momento os detalhes, era, como pregava. entre outros, o mestre de Edouard Manet, Thomas Couture, "semicerrar os olhos e olhar para o objeto natural. Assim fazendo, você o simplifica e elimina os detalhes, de maneira a ver só os contrastes básicos de luz e sombra"30 (Méthode et entretiens d'atelier. Paris, 1867). Décadas depois, Parkhurst proporia um método similar: "Quando você procura por valores você não quer ver detalhes ou coisas, você quer ver apenas as massas e as relações. Você deve desfocar seu olho. O olho focado vê o fato,

\footnotetext{
${ }^{26}$ CAVALLEIRO, H. Op. cit., pp.27-29.

${ }^{27}$ Termo importante para a compreensão das correntes estéticas francesas surgidas na segunda metade do século XIX, o effet, como outras designações técnicas do período, sofreu uma evolução terminológica e tornou-se de aplicação mais abrangente (BOIME, A. The academy and french painting in the nineteenth century. New Haven/London: Yale university Press, 1986, pp.27-29, 167sg.).

${ }^{28}$ Citado em BOIME, A. Idem, p.28.

${ }^{29}$ ALBUQUERQUE, Georgina de. Op cit., p.28.

${ }^{30}$ Citado em BOIME, A. Op. cit., p.26.
} 
e não a relação [...] O método mais comum é semicerrar os olhos, o que atenua os detalhes, mas permite-lhe ver os valores"31.

Uma vez determinadas as grandes massas de luz e sombra, o desenhista podia passar a sua configuração na figura, sobre a marcação do contorno linear realizada na etapa anterior. Como prescrevia Georgina, os limites dessas massas eram normalmente traçadas de maneira semelhante ao limites da figura propriamente dita e elas eram depois preenchidas com os valores mais ou menos uniformes. Algumas academias realizadas por Cavalleiro em seu período de pensionista na França nos permitem ter uma idéia aproximada de como era a aparência usual de uma academia, antes de um modelado mais refinado. Em uma delas ${ }^{32}$, a figura em pé se destaca sobre um fundo não trabalhado e é possível perceber uma grande área de tom médio-escuro que unifica os planos de sombra; os limites lineares geometrizados que separam a área de sombra das de luz permanecem claramente configurados; existe pouca variação dos valores nessas duas áreas, o que confere às mesmas um caráter chapado e tendendo à planaridade; por fim, o que acentua ainda mais a separação entre luz e sombra, as meias-tintas que poderiam fazer o papel de transição são empregadas com parcimônia.

Parkhurst de tal tratamento esquemático defendia a sua eminente utilidade em uma passagem de seu tratado: "Tente analisar o modelado em planos chapados, cada um grande o suficiente para definir uma massa de relevo. Não tema os recortes ao fazer isso. Deixe os valores chapados se encontrarem" 33 . Todavia, um aspecto como o apresentado pela referida academia de Cavalleiro não era pensado pelos acadêmicos como um fim em si, mas antes como o estado provisório de um processo que teria o seu necessário desdobramento. Provavelmente, o aspecto da academia de Cavalleiro, com seu tratamento linear anguloso e a sua valorização da planaridade, tão cara à sensibilidade modernista, não mais significava do que o resultado de um desenho realizado em um período de tempo curto. Algumas outras academias realizadas por Cavalleiro no mesmo período revelam um grau de acabamento - e, portanto, de verossimilhança -, mais acentuado.

31 "Chapter XVII: Values". In: PARKHUSRT, D. B. Op. cit:; com o mesmo objetivo, Parkhurst aconselhava o uso de lentes, como o chamado vidro de Claude.

32 HENRIQUE CAVALLEIRO: Nu masculino de costas, 1920. Carvão sobre papel, 64 x $49 \mathrm{~cm}$. Rio de Janeiro, Museu Dom João VI/EBA/UFRJ, n. Reg. 244.

33 "Chapter XVI: Drawing". In: PARKHUSRT, D. B. Op. cit. 
Todavia, como lembra Boime, a simplificação das massas de luz e sombra em favor do effet, o que que para artistas como Parkhurst ou Cavalleiro representava sobretudo um meio para a realização de obras mais apuradas, passou a ser um fim em si mesmo para outros pintores, já a partir de meados do século XIX. Muitos artistas tenderam a "resumir" o processo acadêmico, que requeria uma técnica laboriosa com respeito ao modelado interno, procurando obter um effet mais nítido: suas figuras adquiriam assim uma aparência chapada com relação ao modelado interno, mas, em compensação, davam uma sensação mais efetiva de relevo, em especial no que dizia respeito às relações entre o motivo principal e o fundo. Exemplos típicos desse procedimento de simplificação das massas de luz e sombra em favor do effet podem ser encontrados em obras célebres de Manet, não por acaso considerado por estudiosos como o já referido Greenberg um dos principais iniciadores das tendências modernistas ${ }^{34}$.

Aqui, seria necessário, porém, frisar a dependência do emprego desse procedimento formal - a "superfície chapada" - com relação às intenções de significação particulares dos $\operatorname{artistas}^{35}$. No caso de Manet, a valorização do caráter bi-dimensional da pintura se devia menos a um qualquer desejo de "pureza" formal do que, principalmente, à sua expressa predileção pela concisão e pela imediaticidade expressiva do quadro ${ }^{36}$. Conceitos como concisão e imediaticidade expresssiva não eram de maneira algumas alheios aos acadêmicos; pelo contrário, eles tinham um lugar de destaque no próprio seio da sua doutrina. Logo é plausível a observação de

${ }^{34}$ Cf. GREENBERG, C. Op. cit., p.102.

${ }^{35}$ Resumindo um racíocinio de T. J. Clark sobre a questão: "Se a superfície chapada era sedutora e aprazível para a arte - como foi para Manet e Cézanne, por exemplo -, isso deve ter acontecido porque foi levada a significar alguma coisa: algum conjunto particular e substancial de qualidades que tinham lugar num retrato do mundo. [...] Em várias ocasiões, o achatamento foi imaginado como uma espécie de análogo do 'Popular' [...] Ou então a superfície chapada podia significar modernidade, com a superfície destinada a evocar as duas dimensões de cartazes, rótulos, impressos de moda e fotografias. Havia pintores que, no que poderia parecer uma abordagem mais diretamente modernista, consideravam aquelas dimensões representativas do fato puro da Arte, do qual outros significados estavam excluídos. [...] E afinal, o caráter inteiriço da superfície podia ser visto - por Cézanne por excelência - como um correlato da uniformidade da visão em si, como a verdadeira forma do nosso conhecimento das coisas" (CLARK, T. J. Op. cit., p.47-48).

${ }^{36} \mathrm{Em}$ um de seus aforismos, Manet declara: "Conciseness in art is a necessity and an elegance. The concise man makes you think; the verbose man bores you. Always move in the direction of conciseness... In a figure, always look for the gratest light and the greatest shadow; the rest will follow naturally" (Citado em NOCHLIN, L. Realism and tradition. 1848-1900. Sources and documents. New Jersey: Prentice-Hall, Inc., 1966, p.78). 
Boime segundo a qual os acadêmicos "freqüentemente apreciavam os quadros feitos pelos pintores independentes que usavam um esquema abrupto de contrastes de valores", embora pusessem limites a tal apreciação. Reciprocamente, os independentes aceitavam a prescrição acadêmica de que um quadro deveria ser caracterizado por um effet intenso, com respeito ao contraste de luz e sombra. Para estes, o principal ponto de discórdia dizia respeito à dissociação da prescrição do effet daquela outra que se referia às meias-tintas, isto é, ao modelado. Como resumiu Boime, os independentes "não lutavam contra os fins estéticos da Academia, mas contra os meios de se conseguir o resultado desejado" 37 .

Nas décadas finais do século XIX, com a ascensão das estéticas independentes e de outras oriundas especialmente das artes aplicadas, quadros caracterizados por contrastes abruptos, agora não mais só de valor, mas também de cor, se tornaram comuns. No Brasil, algumas academias de Candido Portinari, realizados durante seus anos iniciais de formação na ENBA, na década de 1920, apresentam um tratamento sintético na distribuição dos valores e exibem um resultado análogo ao da academia de Cavalleiro. Posteriormente, Portinari incorporaria quase literalmente tal resultado em algumas de suas obras acabadas, como nos painéis do antigo Ministério da Educação e Cultura, já nos anos 1930, que, guiados por uma concepção de pintura decorativa que ganhara grande prestígio no decorrer da 1a República, mantém a mesma enfâse na planaridade e mesma economia no uso dos valores. Cremos que o ponto importante a frisar aqui é que, quando analisada no contexto que procuramos descrever acima, a atitude de um artista "moderno" como Portinari surge não como uma revolta contra a ENBA, mas, essencialmente, como uma resignificação dos meios pedagógicos usuais da instituição; o fenômeno é similar, portanto, àquele que ocorrera na França, décadas antes, quando aspectos da pedagogia da École forma apropriados e resignificados pelos artistas independentes.

Finalizando, cremos que o principal valor que as aproximacões que acima tecemos possui é o de potencialmente poder contribuir no esforço de revisão historiográfica que, já há algumas décadas, tem procurado compreender de maneira mais adequada a contribuição da pedagogia das instituições oficiais de ensino artístico no grande processo de

${ }^{37}$ Idem, p.29. 
transformação da cultura figurativa ocidental verificável a partir da segunda metade do Oitocentos. 